\title{
Parésia Hipocaliemica em Adolescente: Um Caso Clínico
}

\section{Hypokalemic Paresis in Adolescent: A Case Report}

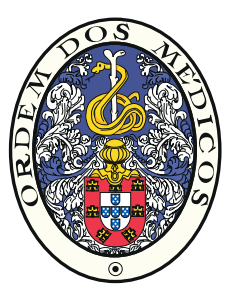

Ana Catarina CARVALHO $\mathbb{1}^{1}$, Joana MATOS 1 , Susana LIRA ${ }^{1}$, Ana REIS ${ }^{1}$

Acta Med Port 2019 May;32(5):400-402 - https://doi.org/10.20344/amp.10497

RESUMO

A paralisia periódica hipocaliémica familiar é uma doença neuromuscular autossómica dominante, rara, caracterizada por crises episódicas de paralisia flácida acompanhadas de hipocaliemia. Apresenta-se o caso de um adolescente do sexo masculino, com 15 anos de idade, observado no Serviço de Urgência de Pediatria por parésia flácida dos quatro membros de início subito e agravamento progressivo. $\mathrm{Na}$ anamnese verificou-se a ingestão de corticoesteroide e antihistaminico no dia anterior por urticária e história familiar de episódios transitórios de paralisia flácida na adolescência, assintomáticos após a $4^{a}$ década de vida, sem diagnóstico estabelecido. Os exames auxiliares de diagnóstico revelaram hipocaliemia $(\mathrm{K}+<2,4 \mathrm{mEq} / \mathrm{L})$, sem hipocaliúria e sem outras alterações. Verificou-se resolução da sintomatologia após suplementação com potássio até normalização da caliemia. A paralisia flácida é uma forma rara de apresentação da hipocaliemia. Diversas etiologias podem estar envolvidas na criança ou adolescente que se apresenta com com paralisia flácida de início agudo. Com a descrição deste caso alerta-se para a importância do conhecimento desta entidade, porque se reconhecidos e tratados apropriadamente, os doentes geralmente recuperam sem sequelas.

Palavras-chave: Adolescente; Canais de Cálcio/genética; Hipocaliémia/genética; Paralisia Periódica Hipocaliémica

\section{ABSTRACT}

Familial hypokalaemic periodic paralysis is a rare autosomal dominant neuromuscular disease characterized by episodic attacks of flaccid paralysis with concomitant hypokalaemia. We present a case of a 15-year-old male adolescent observed in the pediatric emergency department by flaccid paresis of the 4 limbs of sudden onset and progressive worsening. In the anamnesis, corticosteroid and antihistamine intake were observed on the previous day for urticaria and family history of transient episodes of flaccid paralysis in adolescence, asymptomatic after the fourth decade of life, without an established diagnosis. Diagnostic tests revealed hypokalaemia $(\mathrm{K}+<2.4 \mathrm{mEq} / \mathrm{L})$, without hypokaluria and without other changes. Symptomatology resolution after supplementation with potassium was verified until normalization of kaliemia. Flaccid paralysis is a rare form of presentation of hypokalaemia. Several etiologies may be involved in the child or adolescent presenting with acute flaccid paralysis. The description of this case draws attention to the importance of the knowledge of this entity, because if recognized and treated properly, patients usually recover without sequelae.

Keywords: Adolescent; Calcium Channels/genetics; Hypokalemia/genetics; Hypokalemic Periodic Paralysis

\section{INTRODUÇÃO}

A paralisia aguda hipocaliémica corresponde a um grupo heterogéneo de doenças neuromusculares raras que cursam com episódios de fraqueza muscular e hipocaliemia. ${ }^{1-5}$

A paralisia periódica hipocaliémica familiar (PPHF) é a etiologia mais frequente de paralisia periódica, em particular na raça caucasiana, com uma prevalência aproximada de 1:100 000 habitantes..$^{1-3}$ Clinicamente caracteriza-se por episódios súbitos de parésia ou paralisia flácida parcial ou generalizada, reversível. Poupa geralmente os músculos cardíaco, respiratórios, da deglutição e da motilidade ocular, mas estes podem ser afetados na hipocaliemia severa. ${ }^{1-5}$ Nos exames laboratoriais, o valor de potássio sérico está habitualmente diminuído, e os valores de creatinaquinase durante as crises estão frequentemente elevados. . $^{2,4,6}$

Os sintomas geralmente resolvem em poucas horas com correção eletrolítica. ${ }^{1-4}$

Os autores descrevem um caso de paralisia flácida aguda por PPHF num adolescente, cujo diagnóstico é por vezes difícil devido à sintomatologia inespecifica e particularidades desta faixa etária.

\section{CASO CLÍNICO}

Adolescente masculino, de 15 anos de idade, caucasóide, sem antecedentes pessoais de relevo, com história familiar de episódios transitórios de paralisia flácida em dois tios e uma prima maternos, sem diagnóstico estabelecido, assintomáticos após a quarta década de vida. Foi observado no Serviço de Urgência (SU) de Pediatria por tetraparésia flácida de instalação aguda progressiva. A fraqueza muscular foi notada durante a noite, inicialmente com dificuldade para mobilizar os membros superiores e posteriormente os inferiores, agravando-se nas horas seguintes, com plegia dos quatro membros. Tinha sido observado no mesmo SU no dia anterior por exantema urticariforme, tendo sido medicado com metilprednisolona e hidroxizina. Negava episódios prévios semelhantes. Ao exame objetivo apresentava-se hemodinamicamente estável, pele e mucosas coradas e hidratadas. No exame neurológico salientava-se uma tetraparésia flácida de predomínio proximal, simétrica (grau 2/5) e hipo-reflexia simétrica dos membros inferiores. Os músculos eram indolores à palpação e não havia alterações das sensibilidades, da coordenação nem dos pares cranianos. Nos exames laboratoriais foi detetada

1. Serviço de Pediatria. Centro Hospitalar do Tâmega e Sousa. Guilhufe. Portugal.

$\triangle$ Autor correspondente: Ana Catarina Carvalho.72724@chts.min-saude.pt

Recebido: 07 de março de 2018 - Aceite: 09 de junho de 2018 | Copyright @ Ordem dos Médicos 2019 
hipocaliemia 1,9 mEq/L; o hemograma, glicemia, ureia, creatinina, aspartato aminotransferase, alanina aminotransferase, fosfatase alcalina, creatinofosfoquinase, função tiroideia (hormona estimulante da tiroide e tiroxina livre) e restante ionograma (cloro, sódio, fósforo, magnésio e cálcio) eram normais. O eletrocardiograma era normal. Realizou-se ainda uma tomografia computorizada cerebral que foi normal e uma pesquisa de drogas de abuso na urina que foi negativa. Admitiu-se paralisia periódica hipocaliémica familiar (PPHF) com crise precipitada por corticoide e foi efetuada a correção da hipocaliemia com cloreto de potássio $(\mathrm{KCl})$ endovenoso ( $1 \mathrm{mEq} / \mathrm{kg} / 12$ horas). Seis horas após o início da correção endovenosa, por manter hipocaliemia, faz suplementação oral com $1 \mathrm{mEq} / \mathrm{kg}$ de $\mathrm{KCl}$ verificando-se uma rápida melhoria da força muscular. Oito horas após o início do tratamento, o potássio era normal (K+ 4,3 mEq/L) e o doente apresentava resolução completa da sintomatologia. Após remissão dos sintomas, teve alta para o domicílio, referenciado para a consulta de pediatria, informado sobre os fatores desencadeantes das crises e a necessidade de adaptação do estilo de vida. Na consulta externa o diagnóstico de PPHF tipo I foi confirmado por teste genético, sendo detetada uma mutação no gene CACNA1S. Atualmente encontra-se assintomático, medicado com $\mathrm{KCl}(1800 \mathrm{mg} / \mathrm{dia})$ e medidas não farmacológicas, nomeadamente dieta rica em potássio, com baixo teor de sódio e hidratos de carbono e exercício físico moderado.

\section{DISCUSSÃO}

A paralisia flácida é uma forma rara de apresentação da hipocaliemia. ${ }^{4-9}$ Diversas etiologias podem estar envolvidas na criança ou adolescente que se apresenta com paralisia flácida de início agudo.

A PPHF é uma canalopatia neuromuscular hereditária, de transmissão autossómica dominante, com menor penetrância no sexo feminino, o que se traduz em maior prevalência no sexo masculino. ${ }^{2,6,7}$ Aproximadamente $70 \%$ dos casos resultam de mutação no gene CACNA1S do canal de cálcio - paralisia hipocaliémica tipo 1. Este gene codifica a subunidade $\alpha 1$ do canal de cálcio dependente devoltagem tipo L do músculo-esquelético, que está localizado primariamente na membrana do sistema tubular tranverso. Cerca de $10 \%$ dos casos resultam de mutação no gene SCN4A do canal de sódio - paralisia hipocaliémica tipo 2.,6,7

A sintomatologia começa geralmente durante a segunda década de vida. ${ }^{9-12} \mathrm{Em} 60 \%$ dos doentes aparece antes dos 16 anos. ${ }^{2,3}$ A gravidade, frequência e duração das crises é variável, na maioria das vezes ocorrem semanalmente ou mensalmente e podem durar várias horas. A frequência começa a diminuir aos 30 anos de idade, e raramente ocorrem após os 50 anos..$^{2,3}$

As crises são mais frequentes à noite e no início da manhã e são frequentemente precipitadas ou agravadas por baixo consumo ou perdas urinárias/gastrointestinais excessivas de potássio; dieta rica em hidratos de carbono ou sódio; uso de diuréticos, corticoesteroides, insulina ou $\beta$-agonistas; infeções; stress emocional; exercício fisíco vigoroso e exposição ao frio. ${ }^{1-3}$

A PPHF classifica-se em paralítica (75\%), com afeção predominante dos membros e miopática (25\%), na qual as alterações eletromiografias são persistentes, conduzindo a défice motor permanente, principalmente nos membros inferiores, pelos 40 - 60 anos. . $^{8,10,11}$

A história familiar e pessoal sugestiva, associada a paralisia flácida e hipocaliemia, na ausência de miopatia clínica ou eletromiográfica, estabelece o diagnóstico. ${ }^{1,9,11}$ No entanto, a investigação analítica e o eletrocardiograma são importantes na identificação de complicações e no diagnóstico diferencial (paralisia hipocaliémica periódica tireotóxica, miastenia gravis, miopatias metabólicas, síndrome de Guillain-Barré e mielopatia aguda).9,11 A biópsia muscular é pouco específica e deve ser reservada para o diagnóstico histológico de formas atípicas. , $^{910}$ A confirmação genética é desejável, não só como rastreio familiar, mas também para a otimização da escolha terapêutica. ${ }^{9,10,12}$

A apresentação clínica e laboratorial deste caso foi típica e concordante com a literatura, e o diagnóstico confirmado geneticamente.

O tratamento das crises de PPHF inclui a administração de $\mathrm{KCl}$, prevenindo arritmias cardíacas e falência respiratória. 9,11,12 Se a hipocaliemia for inferior a 2,5 mEq/L, ou existir intolerância oral, deve optar-se pela via endovenosa, não ultrapassando o ritmo de $10 \mathrm{mEq} /$ hora, por risco de hipercaliémia de rebound. Foi esta a opção inicial no caso apresentado. Deve também ser evitada a administração de soros glicosados, pelo agravamento da hipocaliemia secundária ao hiperinsulinismo..$^{10,12}$

Após normalização da caliemia há remissão da sintomatologia. ${ }^{1-3} \mathrm{O}$ tratamento preventivo inclui terapêutica não farmacológica e farmacológica. A terapêutica não farmacológica compreende uma dieta rica em potássio, com baixo teor de sódio e hidratos de carbono, sobretudo de absorção rápida, e moderação do exercício físico..$^{3,9,11} \mathrm{~A}$ terapêutica farmacológica inclui potássio oral, diuréticos poupadores de potássio e inibidores da anidrase carbónica. ${ }^{2,9,11} \mathrm{~A}$ acetazolamina apresenta melhores resultados terapêuticos se a mutação for no gene $C A C N 1 A S$, por oposição ao agravamento clínico se a mutação for no gene $S C N 4 A$. ${ }^{10-12}$

Com a descrição deste caso, os autores pretendem alertar para a PPHF enquanto doença rara, mas potencialmente grave. A sintomatologia inespecífica pode atrasar o diagnóstico, mas quando reconhecida e tratada adequadamente os doentes geralmente recuperam sem sequelas, sendo o prognóstico favorável. No entanto, não deve ser esquecida a forma mais grave da doença que cursa com miopatia proximal progressiva habitualmente após os 50 anos.

Deste modo, a PPHF deve ser considerada no diagnóstico diferencial nos quadros de para ou tetraparésia aguda em adolescentes.

\section{PROTECÇÃO DE PESSOAS E ANIMAIS}

Os autores declaram que os procedimentos seguidos estavam de acordo com os regulamentos estabelecidos 
pelos responsáveis da Comissão de Investigação Clínica e Ética e de acordo com a Declaração de Helsínquia da Associação Médica Mundial.

\section{CONFIDENCIALIDADE DOS DADOS}

Os autores declaram ter seguido os protocolos do seu centro de trabalho acerca da publicação de dados.

\section{CONSENTIMENTO DO DOENTE}

Obtido.

\section{REFERÊNCIAS}

1. Aquino J, Rocha AP, Reis AL, Pereira M, Sousa S, Henriques M. Parálisis periódica hipocalémica familiar: una causa poco frecuente de parálisis flácida aguda. Rev Neurol. 2016;63:478-9.

2. Assis TJ, Furtado FF, Mota KS, Medeiros IA, Silva BA. Hypokalemic periodic paralysis type 1: involvement of calcium channel voltagedependent. Rev Neurocienc. 2012;20:588-96

3. Vélez M, Carrizosa J, Cornejo W. Parálisis periódica hipocaliémica familiar: reposte de un caso y revisión del tema. latreia. 2002:114-220.

4. Costa C, Vasconcelos M. Paralisia hipocaliémica na criança-um caso clínico. Saúde Infantil. 2008,30:110-3.

5. Cesur M, Ilgin SD, Baskal N, Gullu S. Hypocalemic paralysis is not a hypocalemic paralysis. Eur J Emerg Med. 2008;15:150-3.

6. Finster J. Primary periodis paralydes. Acta Neurol Scan. 2008;117:14558.

7. Jurkat-Rott K, Lehmann-Horn F, Elbaz A, Heine R, Gregg RG, Hogan

\section{CONFLITOS DE INTERESSE}

Os autores declaram a inexistência de conflitos de interesse na realização do presente trabalho.

\section{FONTES DE FINANCIAMENTO}

Não existiram fontes externas de financiamento para a realização deste artigo.
K. A calcium channel mutation causing hypokalemic periodic paralysis. Hum Mol Genet. 1994;3:1415-9.

8. Ribeiro $R$, Ferreira $M$, Simões $H$, Parreira E. Paralisia periódica hipocaliémica - uma causa rara de tretaparésia em Europeus. Clin Hosp Prof Dr Fernando Fonseca. 2015;3:33-5.

9. Burtey S, Vacher-Coponat H, Berland Y, Dussol B. À propos de deux cas de paralysie périodique hypokaliémique. Nephrol Ther. 2006,2:379-86.

10. Areta-Higuera JD, Algaba-Montes M, Oviedo-García AA. Parálisis periódica hipopotasémica. A propósito de un caso. Semergen. 2014;40:69-72.

11. Ke Q, Luo B, Qi M, Du Y, Wu W. Gender differences in penetrance and phenotype in hypokalemic periodic paralysis. Muscle Nerve. 2013:47:41-5

12. Mota A, Machado V, Peças S, Peças S, Parente S, Balseiro MJ. Quando os músculos não obedecem. Acta Pediatr Port. 2016,47:84-6.

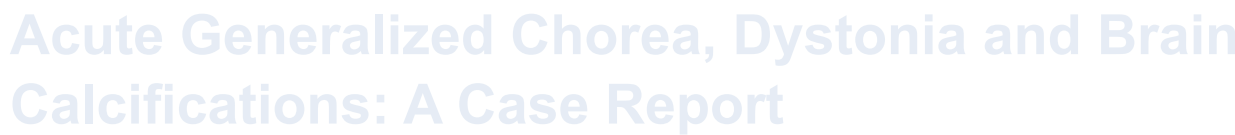

